\title{
CFD analysis of compressible flows in a convergent-divergent nozzle
}

\author{
Sher Afghan Khan ${ }^{a}$, Omar Mohamed Ibrahim ${ }^{a}$, Abdul Aabid ${ }^{\mathrm{a}, \mathrm{b}_{*}}$ \\ ${ }^{a}$ Department of Mechanical Engineering, Faculty of Engineering, International Islamic University Malaysia, PO Box 10, 50728 Kuala Lumpur, Malaysia \\ ${ }^{\mathrm{b}}$ Department of Engineering Management, College of Engineering, Prince Sultan University, PO BOX 66833, Riyadh 11586, Saudi Arabia
}

\section{A R T I C L E I N F O}

\section{Article history:}

Received 2 January 2021

Received in revised form 28 February 2021

Accepted 4 March 2021

Available online 26 March 2021

\section{Keywords:}

CFD

Compressible flow

C-D nozzle

ANSYS simulation

Mach number

\begin{abstract}
A B S T R A C T
A Nozzle is a mechanical device that uses pressure energy and fluid enthalpy to increase the outflow velocity and control fluid flow direction. To obtain the nozzle duct's shock pattern, the flow inside the nozzle must be supersonic with a Mach number greater than one. Experimentally, the shock pattern is obtained for a nozzle with a Mach number 2 and nozzle pressure ratio (NPR) equivalent to 7 and below. For Mach $M=2$, the needed NPR is equal to 7.82 for correct expansion.. When the NPR is greater than 7.82, flow from the nozzles is under-expanded. For NPR less than 7.72 the flow from the nozzle is over-expanded. In this paper, the computational fluid mechanics (CFD) technique was used to simulate the nozzle flow based on the experimental investigation. A two-dimensional transient compressible flow of air through a supersonic nozzle was simulated using ANSYS fluent software. A time-dependent flow using the density-based implicit solver was useds to analyze the simulation results. The results illustrate that the CFD technique simulates the fluid flows and the formation of shock in a duct and gives useful information about fluid dynamics analysis. (c) 2021 Elsevier Ltd. All rights reserved.

Selection and peer-review under responsibility of the scientific committee of the International Conference on Smart and Sustainable Developments in Materials, Manufacturing and Energy Engineering.
\end{abstract}

\section{Introduction}

A Nozzle is a mechanical system designed to use pressure energy and fluid enthalpy to increase the outflow velocity and regulate the direction of fluid flow. Nozzles are used in subsonic and supersonic velocity applications, and knowing the flow behavior of nozzles is vital for successful development. The convergent nozzle cross-section area decreases smoothly from a considerable value to a small number, which can be described as $A_{\text {inlet }}>A_{\text {outlet }}$, causing an increase in the pressure and velocity of the fluid at the exit side, but a constant parameter remains the mass flow rate. A convergent-divergent nozzle, on the other hand, contains a throat, and this nozzle is shown to increase the velocity smoothly from a small value to a substantially enormous amount as $A_{\text {outlet }}>A_{\text {inlet }}$, creating a subsonic acceleration at the minimum region of the throat to a maximum velocity. A C-D nozzle has the lowest pressure and speed of fluid flow at the outlet. Fluid viscosity is a molecular property that tests the fluid's internal

* Corresponding author at: Department of Engineering Management, College of Engineering, Prince Sultan University, PO BOX 66833, Riyadh 11586, Saudi Arabia.

E-mail addresses: abdul.aabid@live.iium.edu.my, aaabid@psu.edu.sa (A. Aabid). resistance to actual fluid deformation, whether liquids or gases have finite viscosities connected to them [1]. External flow is the flow that flows past a projectile on a free surface. Inside the boundary layers, the viscous effects of internal flows are confined. The flat plate, cylinders or spheres, and airfoils are a true application of external flows [2].

For supersonic flow generation, a C-D nozzle is utilized. A nozzle without an expanding component will never produce supersonic air [3]. There are three-dimensional predicted fluid flows; the term one, two, or three-dimensional flow refers to the amount of organized space needed to demonstrate flow. Typically, physical motion appears to be three-dimensional. It is possible to reduce a three-dimensional issue to a two-dimensional one and then simplify it to a one-dimensional one. The continuity equation, the energy equation, and the momentum equation are used as the three main governing equations of motion for solution techniques $[4,5]$. The several studies have been reported on the flow of CD nozzle with sudden expansion duct. The researchers also controlled the flow to reduce the base drag and investigated base and wall pressure [6-19] via experimentations. The flow of fluid through a stream or pipe where the flow parameters in only one planar are assumed to change significantly is known as one-dimensional flow. The nozzle's generic formula was manually calculated in the 


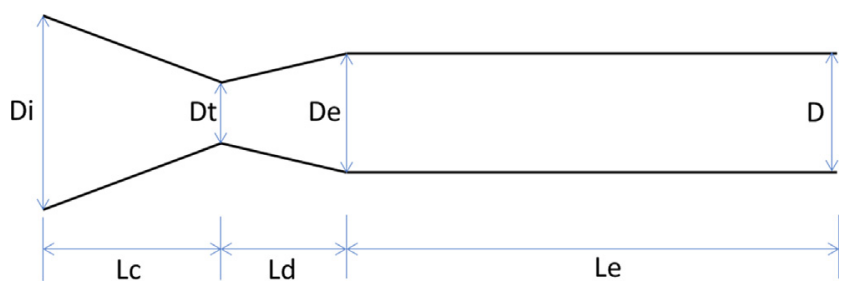

Fig. 1. Nozzle with Enlarged Duct.

convergent nozzle flow phase and analyzed by the ANSYS flux program compared to the effects [20,21]. A numerical simulation of a C-D nozzle using ANSYS at the supersonic Mach number for a duct flow was studied [22]. The considered duct length is $\mathrm{L}=$ $10 \mathrm{D}$ for a diameter ratio of 1.6. For Mach numbers 1.87, 2.2, and 2.58 [23], the flow is simulated at various expansion speeds for the exit Mach number. In the 3 to 11 range, the nozzle pressure ratio at which the simulations were performed. The Turbulence k-turbulence model was selected for the simulations. Later, the same concept is used for area ratios, Mach number, nozzle pressure ratio, and L/D using ANSYS [24-29]. The numerical simulations are also used for investigating the flow field around the wedge [30,31], non-circular cylinder [32,33]. In a recent study on fluid flows, the researchers utilized the soft computing method via experimental design $[23,34,35]$.

During wind tunnel experiments, shock waves occur in the C-D nozzle as the flow moves through the nozzle. The method of carrying out this experiment is expensive. The CFD is then used to achieve the findings because it is less costly and more precise. The main objective of using the CFD technique is to model and evaluate a 2-D transient flow, including the compressibility effects through a C-D nozzle. This research seeks to obtain the CFD shock waves and then equate the experimental findings with the results of the CFD.

\section{Methodology}

The current work aims to use the CFD method to apply a transient compressible flow through a two-dimensional C-D nozzle. However, optimization of different factors such as Mach number, NPR, density-based implicit solver, etc., using ANSYS tools. The CFD simulations were done to obtain the preliminary results to achieve these research goals: The C-D nozzle modeling was performed fluently in ANSYS 18.1. Fig. 1 illustrates each segment's symbol.

As a first stage, the lines are established and then linked based on the design nozzle. Therefore, the 2D surface was created, shown in Fig. 2, using surfaces from the sketches option.

A C-D nozzle with a Mach number 2 and an L/D of 6 is used to conduct the C-D nozzle's detailed aspects shown in Table 1. After

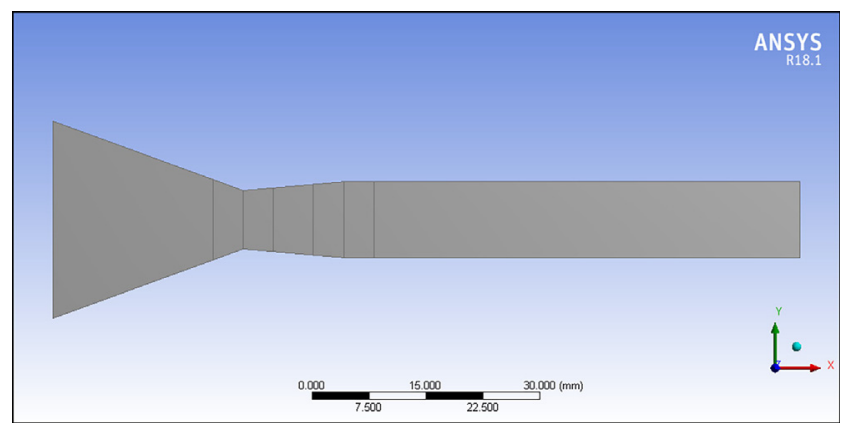

Fig. 2. Two-dimensional CFD model of the nozzle for Mach number 2.
Table 1

Details of the C-D Nozzle for Mach number $M=2$.

\begin{tabular}{ll}
\hline Segment & Mach number 2 \\
\hline Inlet diameter (Di) & $25.9 \mathrm{~mm}$ \\
Throat diameter (Dt) & $7.7 \mathrm{~mm}$ \\
Exit diameter (De)/Extended diameter (D) & $10 \mathrm{~mm}$ \\
Convergent length (Lc) & $25 \mathrm{~mm}$ \\
Divergent length (Ld) & $13.2 \mathrm{~mm}$ \\
Extended length (Le) & $60 \mathrm{~mm}$ \\
Convergent angle (Ac) & 20-degree \\
Divergent length (Ad) & 5-degree \\
\hline
\end{tabular}

completion of the model, the surface body is segregated into seven prominent faces. The faces are split into many faces to change the mesh and add the correct boundary conditions (Table 2).

\subsection{Meshing}

The meshing is done once a 2D model was obtained and perform it a meshing tool of ANSYS workbench (fluid flow-fluent) was used. A default mesh parameter was chosen: CFD, solver preference is fluent, and relevance was set to 0. Initially, the mesh that

Table 2

Pre-processing details.

\begin{tabular}{ll}
\hline Models & Energy: on \\
& Viscous: Standard k-e \\
Materials & Density: Ideal gas \\
& $C_{p}: 1006.43 \mathrm{~J} / \mathrm{kg} \mathrm{K}$ \\
& Viscosity: Sutherland \\
& Mean molecular mass: $28.966 \mathrm{~g} / \mathrm{mol}$ \\
& Inlet Pressure $=691036.5 \mathrm{~Pa}$ \\
Boundary Conditions & Inlet temperature $=300 \mathrm{~K}$ \\
& Gauge pressue $=101325 \mathrm{~Pa}$ \\
& Outlet Pressure $=0 \mathrm{~Pa}$ \\
& Outlet temperature $=300 \mathrm{~K}$ \\
Solution controls & Courant number: 5 \\
Solution initialization & Initialization Method: Standard Initialization \\
& Compute from: Inlet \\
Run calculation & Number of iterations 1000 \\
\hline
\end{tabular}

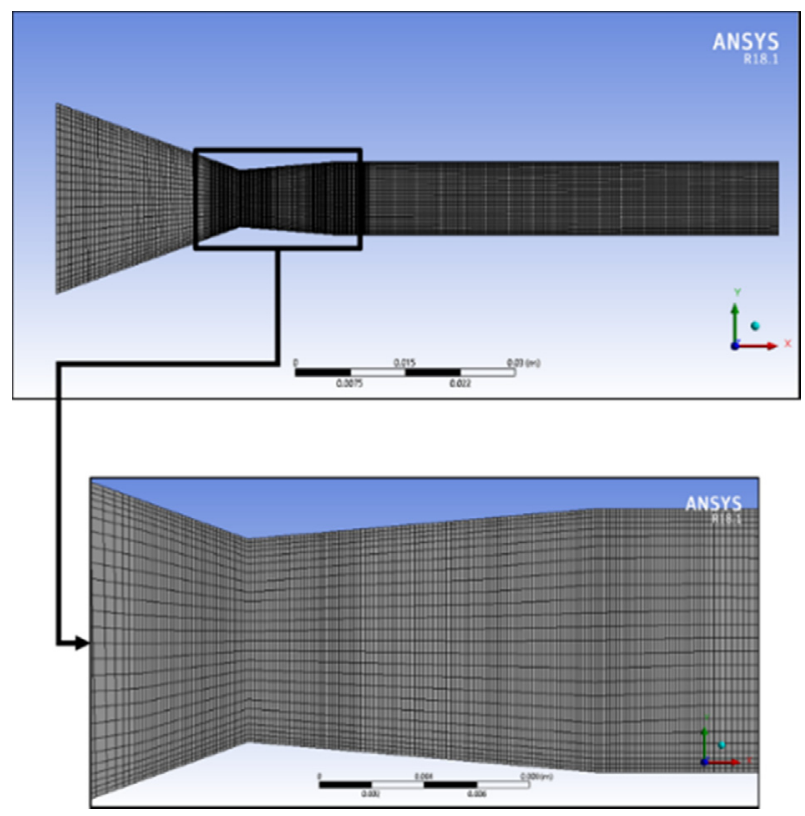

Fig. 3. CFD mesh model with the structured type of mesh. 


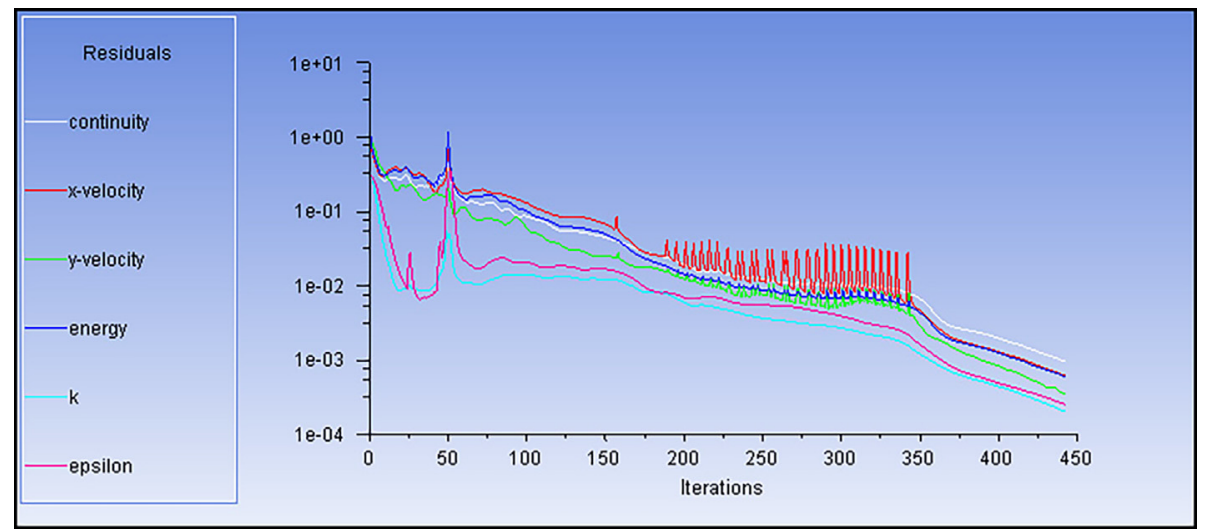

Fig. 4. Iterations-solution converged.

has emerged is called an unstructured mesh, and in most situations, this mesh cannot be used to get reliable results. The mesh can be transformed into a structured type of mesh by using face meshing since the faces are rectangular shape. The number of splits in the inlet, walls, and outlet varies during selecting the mesh number of element divisions. The cells should be more separated when the organized mesh occurs. By adding edge scaling, the number of divisions can be changed. A total of eight-edges have been chosen, and there are 20 divisions. The wall is divided into three edge sizes, and the number of divisions is equal to 40,30 , and 250 , respectively.

Small cells appear in the nozzle after the application of the division in Fig. 3. Because of the small division (high density) in the throat, the black component happens, as shown in Fig. 3 (zoom view). The nozzle contours can be distinguished at the end of the meshing process by defining names like inlet, outlet, and walls. Next, in the hierarchical interconnected model, rational boundary constraints are employed. The mesh was tested fluently, and there were no critical errors reported. Since the flow is compressible, the density-based implicit solver is used to get the data.

The iteration was set to 1000 (arbitrarily number), but the solution converged within this range and is shown in Fig. 4. This method applies to the NPR equivalent to 7.82 , which is the correct expansion.

\section{Results and discussion}

Three sub-sections to explain the outcomes of this work are added in this section. Firstly, the mesh independence test is con-

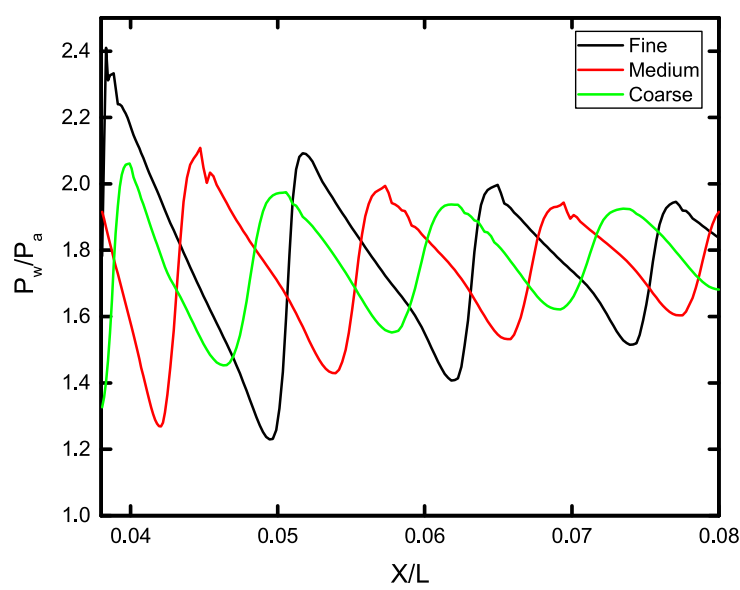

Fig. 5. Three types of mesh. ducted to demonstrate the mesh size accuracy. Secondly, the validation section will display the experiment results chosen from the literature [36]. Thirdly, the results portion that is carried out using CFD and the discussion in this project illustrates and describes the relationship between the validation part and the outcomes.

\subsection{Mesh independence study}

The mesh independence study (MIS) is conducted before proceeding with the findings. By considering only $\mathrm{L} / \mathrm{D}=6$, Mach number 2 with NPR of 7.82, which is the correct expansion, the wall pressure was checked for MIS. Three different kinds of mesh are available, which are coarse, fine, and medium. The number of nodes and elements for the coarse form is 7500 and 7160 in sequence. For the medium form, 9407 and 8976 are the number of nodes and elements, respectively. Although the number of nodes is 12,042 , and the elements are 11,570 . For the fine form, the time required for the fine, medium, and coarse solution to converge was 40,68 , and $110 \mathrm{~s}$. For the three types of mesh, Fig. 5 shows the wall pressure behavior divided by the atmospheric pressure. It also indicates that the maximum value of wall pressure is derived from the fine mesh by atmospheric pressure, and the lowest is coarse. The results are obtained using a clock speed of $3.4 \mathrm{GHz}$ and $8 \mathrm{~GB}$ RAM with Intel i7 core Toshiba.

\subsection{Method validation}

Within a duct representing a supersonic combustion isolator, experiments were carried out to study the mass flow properties of a shock train [36]. The isolator consists of a rectangular tube that has a constant area $(25 \mathrm{~mm}$ by $30 \mathrm{~mm})$. With the pressure transducer and the mercury manometer connected to the taps on the isolator surface, the axial pressure's magnitude is measured (Fig. 6). The shock formation of the pressure duct can be seen from the shadowgraph (Fig. 6a) compared to the present pressure contours (duct), which is similar to Fig. $6 \mathrm{~b}$.

\subsection{Contours}

\subsubsection{Pressure flows}

The fuel is pumped and mixed with a supersonic stream without shock losses to conduct supersonic combustion-the combustion results in creating the shock pattern, coupled with a prolonged increase in pressure. The pressure rise associated with the shock train may be too strong to divide the incoming boundary layer. Therefore, high losses that cause disruptions in the combustion chamber can occur. These disruptions will lead to problems that will not start. A passage known as an isolator is connected 


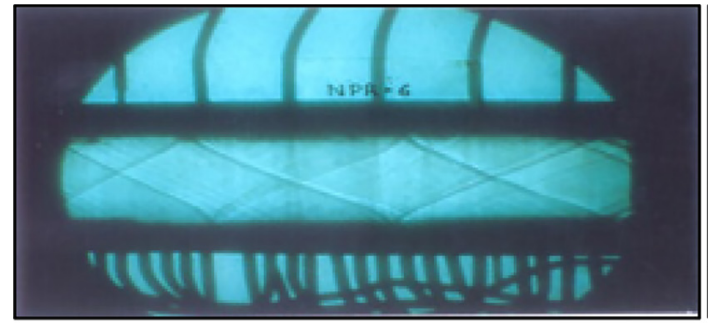

(a)

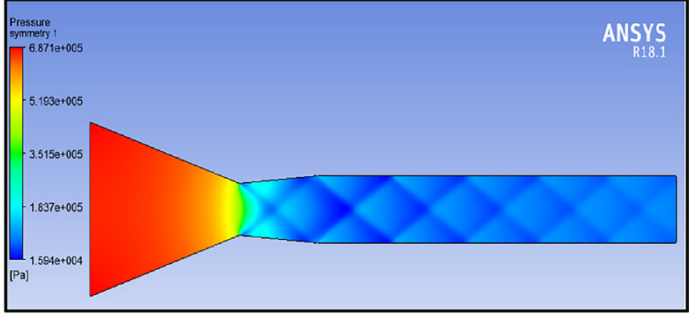

(b)

Fig. 6. Shadowgraph for a specific case $\mathrm{L} / \mathrm{H}=6$ (a) Experimental duct [36] (b) CFD.

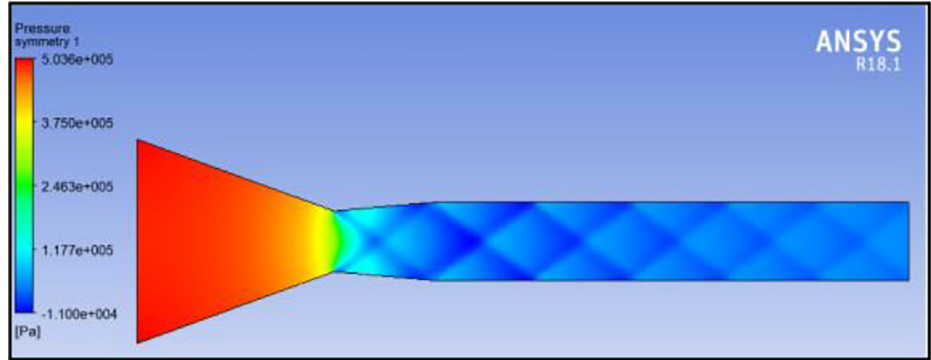

(a)

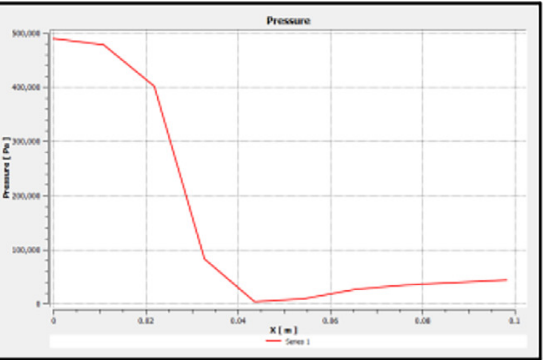

(b)

Fig. 7. Pressure flow through the nozzle $(N P R=6)(a)$ contour $(b)$ plot.

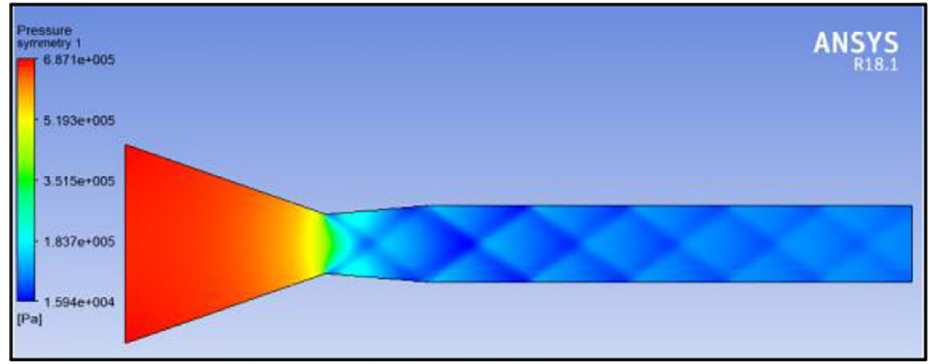

(a)

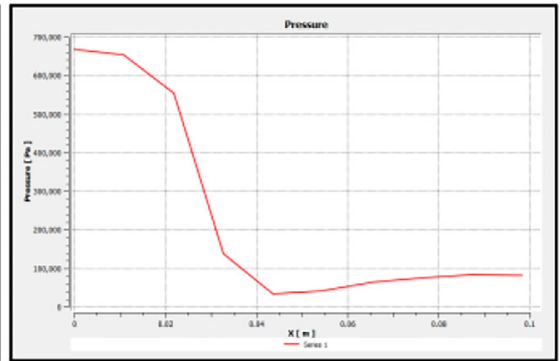

(b)

Fig. 8. Pressure flow through the nozzle (NPR $=7.82$ ) (a) contour (b) plot.

between the inlet and the combustion chamber to separate the shock waves. The disturbances will, therefore, not get into the inlet. We need to achieve the efficiency of an isolator in the supersonic flow of Mach number 2 in this project. The duct's L/D ratio is 6 . The shock pattern is analyzed at NPR 6 and 7 by conducting the experiment, which is presented in the validation section. Overexpansion happens when the pressure is lower than the ambient pressure at the outlet. However, the testers attempted to apply
NPR 7.82, which is the correct extension, but they were unable to decide because of the lack of an experimental setup. In this work, NPR 7.82 and NPR 8.2 were obtained at higher Mach numbers with correct expansion, which is under expansion. When the pressure at the outlet is equal to the ambient pressure, there is the correct expansion.

As shown in Fig. 7a, the inlet's pressure is high, decreasing as it gets nearer to the outlet. In the throat, the shock pattern continues

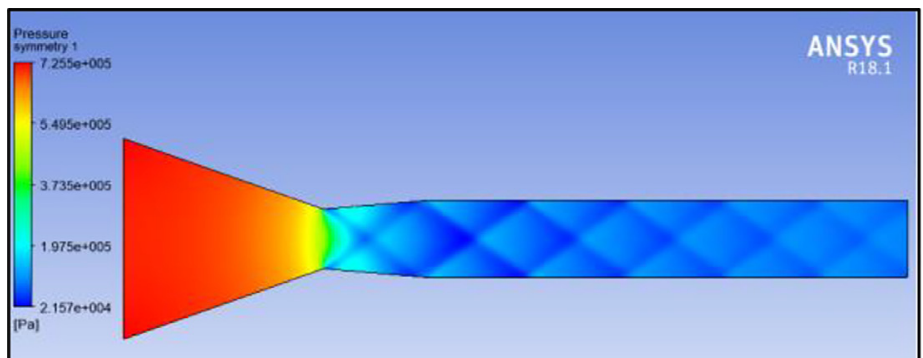

(a)

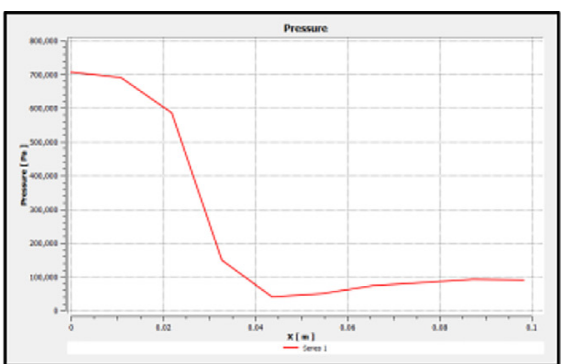

(b)

Fig. 9. Pressure flow through the nozzle $(N P R=8.2)$ (a) contour (b) plot. 


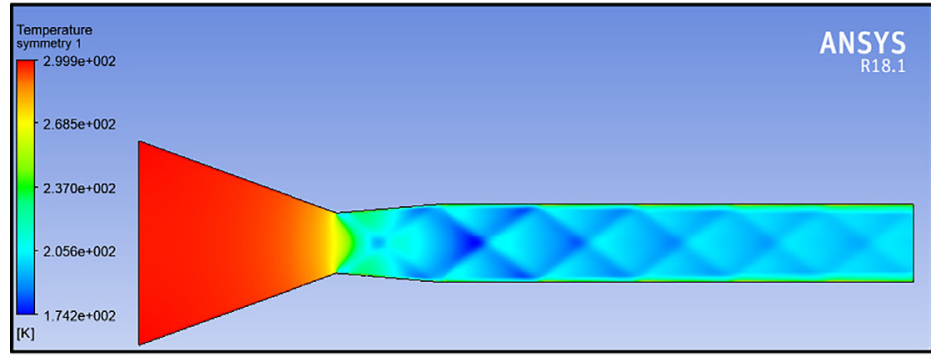

(a)

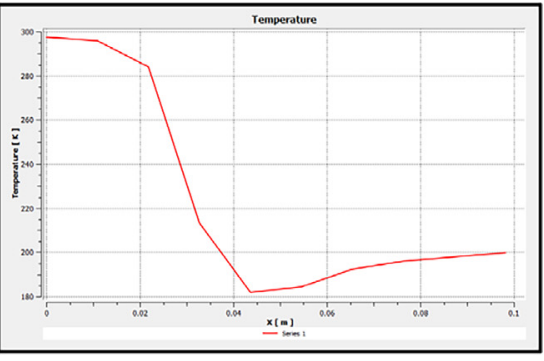

(b)

Fig. 10. Temperature flow through the nozzle $(N P R=6)(a)$ contour (b) plot.

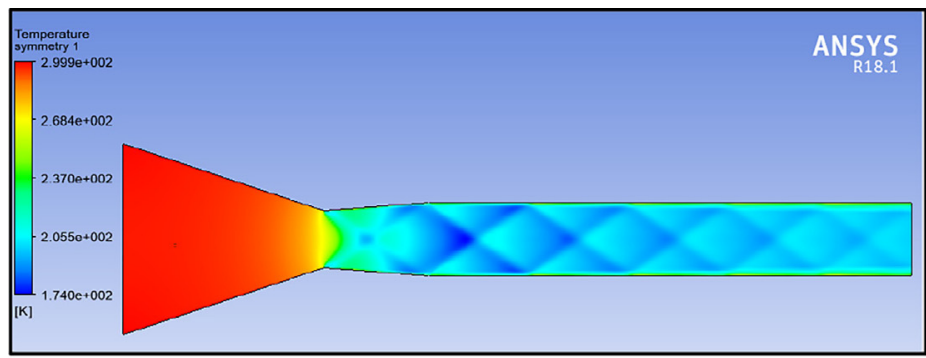

(a)

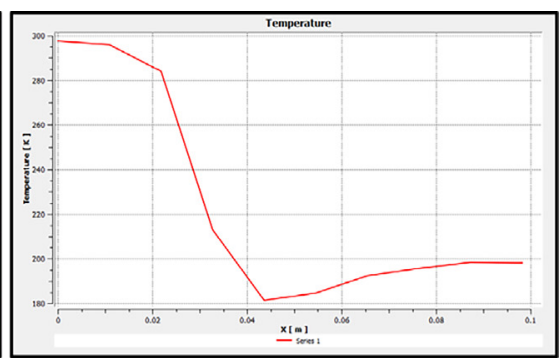

(b)

Fig. 11. Temperature flow through the nozzle $(N P R=7.82)$ (a) contour (b) plot.

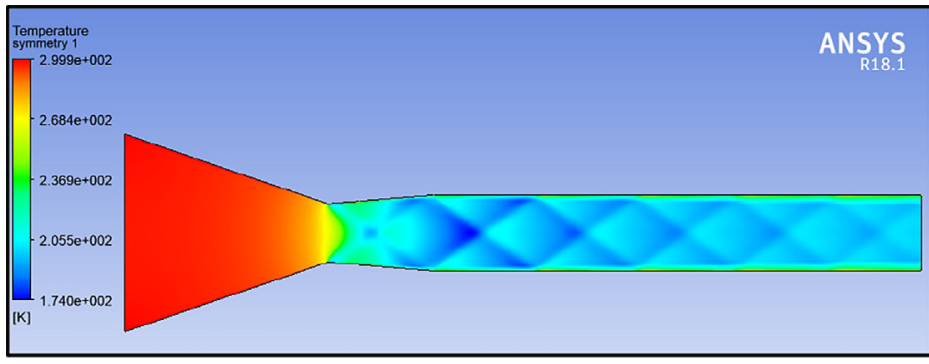

(a)

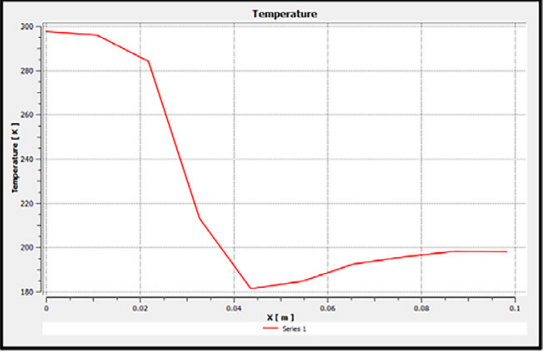

(b)

Fig. 12. Temperature flow through the nozzle (NPR = 8.2) (a) Contour (b) plot.

through the duct until it reaches the outlet. As shown in Fig. 7b, the inlet's pressure is $4.90 \times 10^{5} \mathrm{~Pa}$. The outlet pressure is around $4 \times$ $10^{4} \mathrm{~Pa}$. The inlet's pressure is maximum, and as it gets nearer to the outlet, it decreases. It disappears afterward. As shown in Fig. 8a, the inlet's pressure is $6.65 \times 10^{5} \mathrm{~Pa}$. The pressure is around $9 \times$ $10^{4} \mathrm{~Pa}$ at the outlet (Fig. 8b). The inlet's pressure is maximum, and as it gets nearer to the outlet, it decreases. It disappears after- ward. The pressure is $7.08 \times 10^{5} \mathrm{~Pa}$ at the inlet, shown in Fig. 9a. At the same time, the outlet pressure is around $9.7 \times 10^{4} \mathrm{~Pa}$ (Fig. 9b).

\subsubsection{Temperature flows}

Based on the temperature contours, the inlet's temperature was found to be maximum, and it decreases as it gets closer to the outlet in Fig. 10a. The temperature is $297 \mathrm{~K}$ at the inlet, as shown in

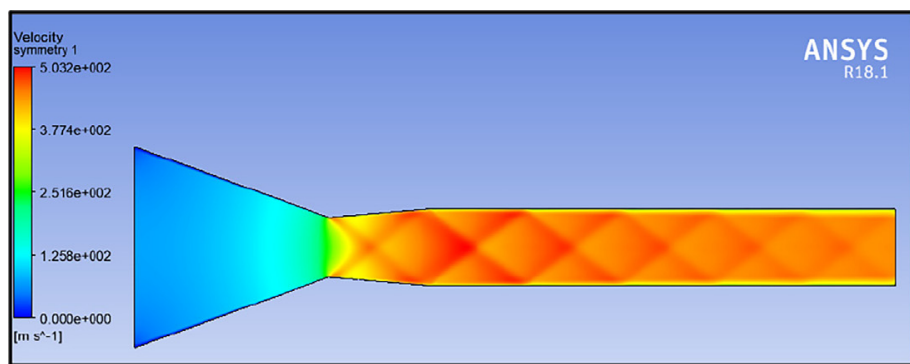

(a)

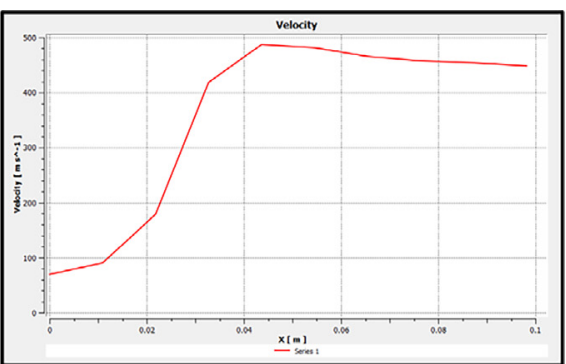

(b)

Fig. 13. Velocity flow through the nozzle $(N P R=6)$ (a) Contour (b) plot. 


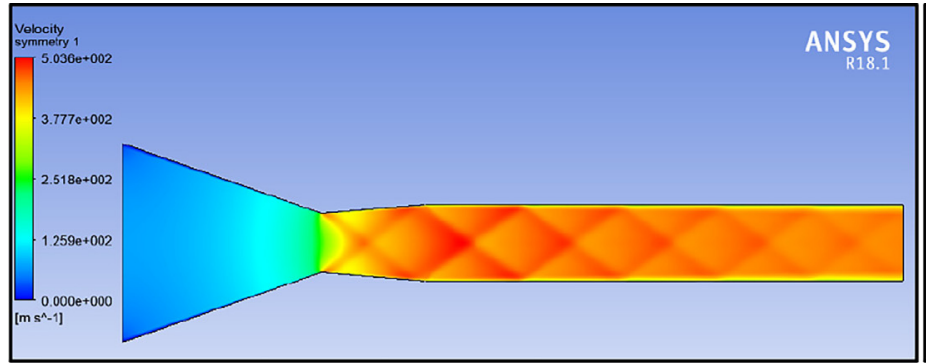

(a)

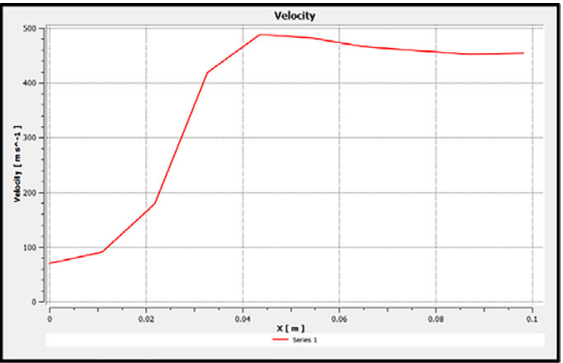

(b)

Fig. 14. Velocity flow through the nozzle $(N P R=7.82)$ (a) Contour (b) plot.

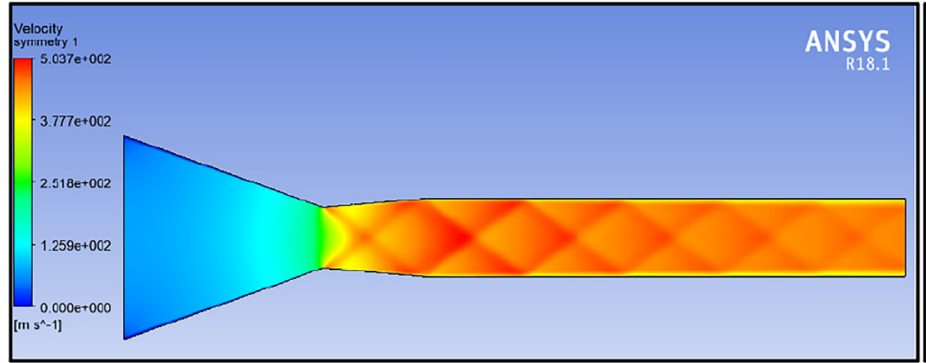

(a)

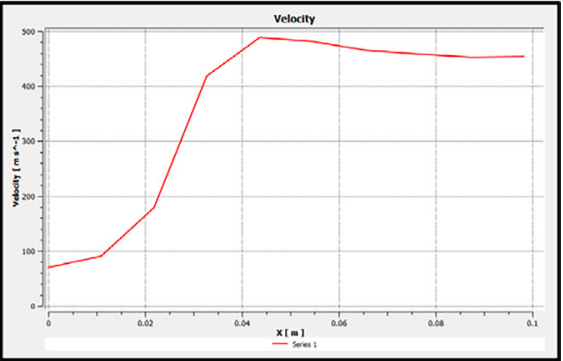

(b)

Fig. 15. Velocity flow through the nozzle $(N P R=8.2)$ (a) Contour (b) plot.

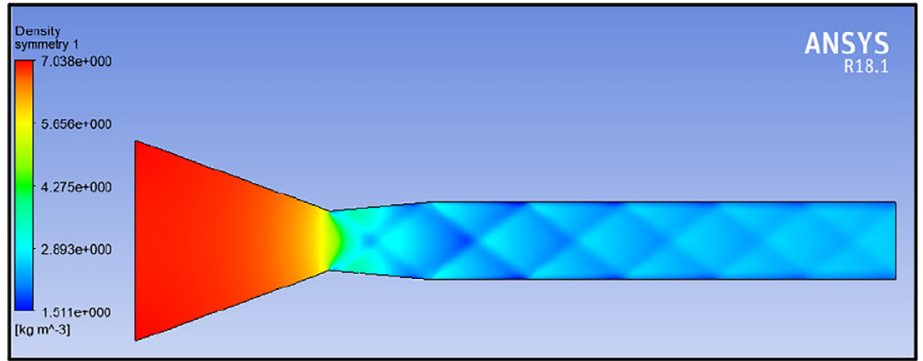

(a)

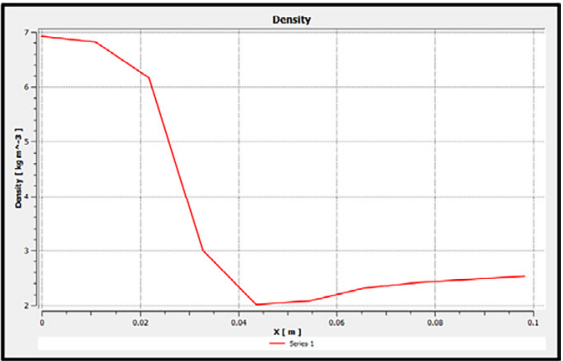

(b)

Fig. 16. Density flow through the nozzle $(N P R=6)(a)$ contour (b) plot.

Fig. 10b. The temperature at the outlet, in comparison, is $200 \mathrm{~K}$. At the inlet, the temperature is highest, decreasing as it comes closer to the outlet in Fig. 11a. The temperature is $297 \mathrm{~K}$ at the inlet, as shown in Fig. 11b, Simultaneously, the temperature at the outlet is $198 \mathrm{~K}$. At the inlet, the temperature is highest, decreasing as it comes closer to the outlet in Fig. 12a. The temperature is $297 \mathrm{~K}$ at the inlet, as shown in Fig. 12b.

In comparison, the temperature is $198 \mathrm{~K}$ at the outlet. This means that the nozzle's temperature variation is high at the intel zone, whereas low outlet and duct zone. By applying the inlet pressure, shock moves inside the body, resulting in motion and pressure loss, the temperature will be reducing. Moreover, in each NPR, the numerical values are changing with changes in NPR.

\subsubsection{Velocity flows}

Based on the contours of the velocity, in Fig. 13a, the speed is low at the inlet, increasing as it comes closer to the outlet. The speed is $70 \mathrm{~m} / \mathrm{s}$ at the inlet. At the same time, $450 \mathrm{~m} / \mathrm{s}$ is the

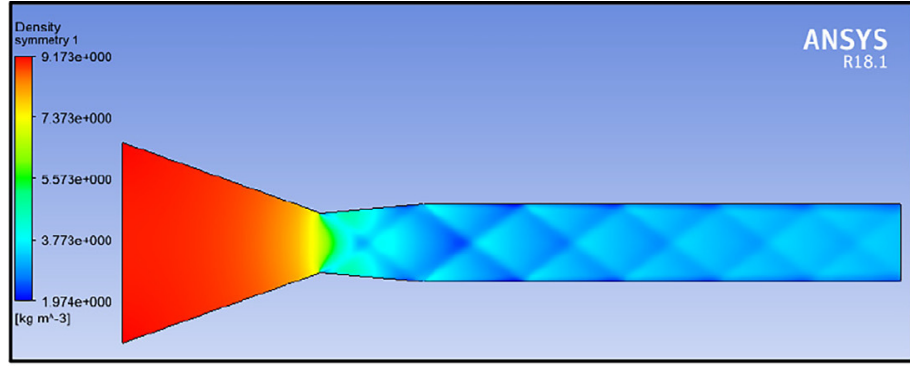

(a)

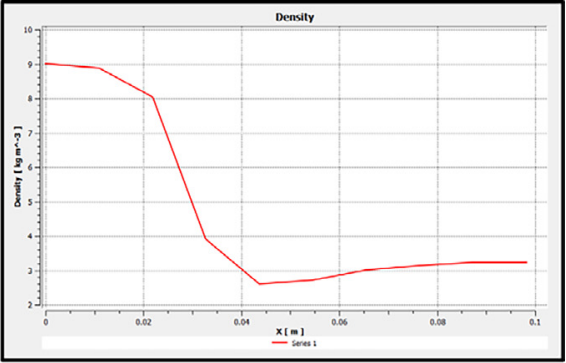

(b)

Fig. 17. Density flow through the nozzle $(N P R=7.82)$ (a) contour (b) plot. 


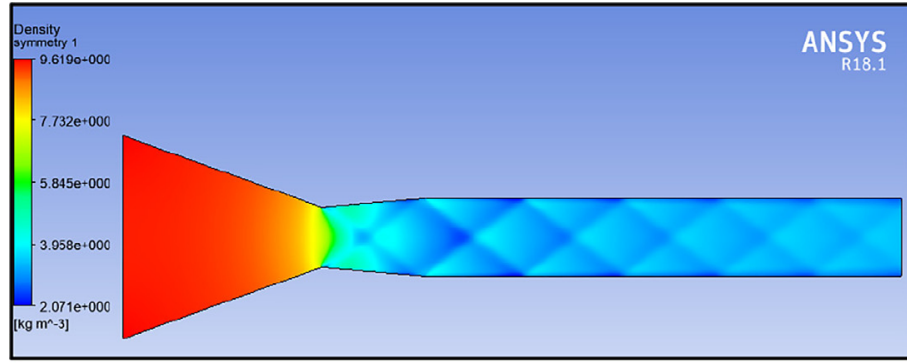

(a)

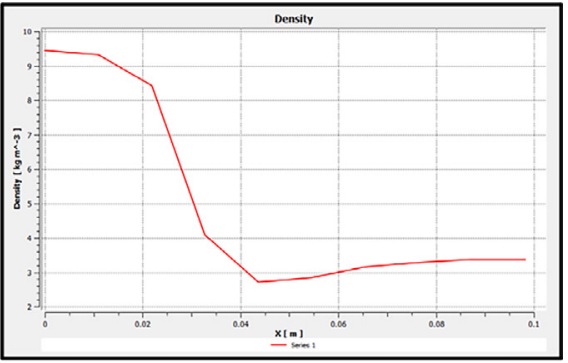

(b)

Fig. 18. Density flow through the nozzle $(N P R=8.2)$ (a) contour (b) plot.

velocity at the outlet. In Fig. 13b, these details are given. In Fig. 14a, the speed is low at the inlet, increasing as it gets nearer to the outlet. The speed is $70 \mathrm{~m} / \mathrm{s}$ at the inlet. $450 \mathrm{~m} / \mathrm{s}$ is the velocity at the outlet. In Fig. 14b, these details are given. Now in Fig. 15a, at the inlet, the velocity is small, increasing as it comes closer to the outlet. The speed is $70 \mathrm{~m} / \mathrm{s}$ at the inlet.

At the same time, $450 \mathrm{~m} / \mathrm{s}$ is the velocity at the outlet (Fig. 15b).

When these results compare to the temperature contours or pressure contours, it is opposite variations. This is due to the fundamental principle of Bernoulli's equation. Based on that, when pressure increases, the velocity will decrease, which can be seen in our results. A higher range of velocity is found in the duct. Whereas at the inlet, the velocity is low, but the pressure is high. When there is motion inside the duct of flow, the velocity increases; after the throat, there is a sudden increment in velocity; hence, it reaches a high Mach number. Indeed, this fundamental study can state in many fluid dynamics literature.

\subsubsection{Density flows}

It has been found that the fluid flow density varies gradually from inlet to outlet through the nozzle based on the effects of density contours (Fig. 16a). Fig. 16b indicates the density, which is around $6.9 \mathrm{~kg} / \mathrm{m}^{3}$, at the inlet. At the same time, $2.5 \mathrm{~kg} / \mathrm{m}^{3}$ is equal to the density at the outlet. Fig. 17a indicates the fluid flow density changes through the nozzle progressively from inlet to outlet. Whereas Fig. 17b indicates the density, which is around $9 \mathrm{~kg} / \mathrm{m}^{3}$ at the inlet, and $3.2 \mathrm{~kg} / \mathrm{m}^{3}$ is equal to the outlet's density. Fig. 18a indicates the fluid flow density increases through the nozzle steadily from inlet to outlet. Fig. 18b shows the density, which is around $9.5 \mathrm{~kg} / \mathrm{m}^{3}$, at the inlet. At the same time, $3.3 \mathrm{~kg} / \mathrm{m}^{3}$ is equal to the density at the outlet. After observing the density results, it did not find constant density because it is in the supersonic range and is a compressible type of flow. Moreover, the kind of solver selected in this study is density-based, which shows how density influences the form of flow inside the nozzle. Hence, based on the present results, the density is high in the inlet region, whereas it is changed after flow motion.

\section{Conclusion}

Based on the above discussion, the following conclusions are drawn:

- The results show the formation of the shock wave train with capturing of the shock waves in the isolator. For supersonic combustion, the fuel injection should be at supersonic Mach numbers was found from this study.

- The results obtained can be used as the benchmark results for simulating the flow at Mach numbers other than Mach 2. Due to the presence of the shock train, fluctuations in the pressure were successfully observed using CFD method.
- The flow parameters like pressure, temperature, density, and velocity are shown as a function of the isolator's axial length. The isolation of the shock train can be isolated by varying the backpressure.

\section{CRediT authorship contribution statement}

Sher Afghan Khan: Conceptualization, Supervision, Formal analysis, Investigation, Writing - review \& editing. Omar Mohamed Ibrahim: Writing - original draft, Software, Investigation. Abdul Aabid: Conceptualization, Data curation, Methodology, Writing - original draft, Writing - review \& editing.

\section{Declaration of Competing Interest}

The authors declare that they have no known competing financial interests or personal relationships that could have appeared to influence the work reported in this paper.

\section{References}

[1] V. Tapasvi, M.S. Gupta, T. Kumaraswamy, Designing and simulating compressible flow in a nozzle, Int. J. Eng. Adv. Technol. 6 (2015) 46-54.

[2] E. Rathakrishnan, Steady one-dimensional flow, Appl. Gas Dyn. (2019) 43-112, https://doi.org/10.1002/9781119500377.ch2.

[3] S. Issue, CFD analysis on convergent nozzle, Int. J. Res. Advent Technol (March) (2019) 8.

[4] G. Xu, K.D. Luxbacher, S. Ragab, J. Xu, X. Ding, Computational fluid dynamics applied to mining engineering: a review, Int. J. Mining, Reclam. Environ. 31 (4) (2017) 251-275, https://doi.org/10.1080/17480930.2016.1138570.

[5] F. Alobaid, Comput. Fluid Dyn. 57 (1) (2018).

[6] A. Aabid, S.A. Khan, M. Ahmed, A. Baig, A.R. Reddy, Investigation of flow growth in a duct flows for higher area ratio, IOP Conf. Ser. Mater. Sci. Eng. 1057 (012052) (2021) 10, https://doi.org/10.1088/1757-899X/1057/1/012052.

[7] A. Aabid, S.A. Khan, M. Ahmed, A. Baig, K.S. Rao, Effect of control on the duct flow at high mach numbers, IOP Conf. Ser. Mater. Sci. Eng. 1057 (012053) (2021) 9, https://doi.org/10.1088/1757-899X/1057/1/012053.

[8] M.N. Akhtar, E.A. Bakar, A. Aabid, S.A. Khan, Control of CD nozzle flow using microjets at mach 2.1, Int. J. Innov. Technol. Explor. Eng. 8 (9 Special Issue 2) (2019) 631-635, https://doi.org/10.35940/ijitee.I1128.0789S219.

[9] M.N. Akhtar, E.A. Bakar, A. Aabid, S.A. Khan, Effects of micro jets on the flow field of the duct with sudden expansion, Int. J. Innov. Technol. Explor. Eng. 8 (9 Special Issue 2) (2019) 636-640, https://doi.org/10.35940/ijitee. I1129.0789S219.

[10] S.A. Khan, A. Aabid, Z.I. Chaudhary, Influence of control mechanism on the flow field of duct at mach 1.2 for area ratio 2.56, Int. J. Innov. Technol. Explor. Eng. 8 (6 Special Issue 4) (2019) 1135-1138, https://doi.org/10.35940/ijitee. F1236.0486S419.

[11] A. Aabid, A.G.M. Fharukh, Sher Afghan Khan, Experimental investigation of wall pressure distribution in a suddenly expanded duct from a convergentdivergent nozzle, in: 2019 6th IEEE International Conference on Engineering Technologies and Applied Sciences (ICETAS), 2019, p. 6, https://doi.org/ 10.1109/ICETAS48360.2019.9117428.

[12] A. Aabid, S. Afghan Khan, Determination of wall pressure flows at supersonic mach numbers, Mater. Today:. Proc. (2020), https://doi.org/10.1016/ j.matpr.2020.06.538

[13] S.A. Khan, A. Aabid, C.A. Saleel, Influence of micro jets on the flow development in the enlarged duct at supersonic mach number, Int. J. Mech. Mechatron. Eng. IJMME-IJENS 19 (01) (2019) 70-82. 
[14] M.H. Azami, M. Faheem, A. Aabid, I. Mokashi, S.A. Khan, Inspection of supersonic flows in a CD nozzle using experimental method, Int. J. Recent Technol. Eng. 8 (2S3) (2019) 996-999.

[15] M.H. Azami, M. Faheem, A. Aabid, I. Mokashi, S.A. Khan, Experimental research of wall pressure distribution and effect of micro jet at mach 1.5, Int. J. Recent Technol. Eng. 8 (2S3) (2019) 1000-1003.

[16] S.A. Khan, I. Mokashi, A. Aabid, M. Faheem, Experimental research on wall pressure distribution in C-D nozzle at mach number 1.1 for area ratio 3.24, Int. J. Recent Technol. Eng. 8 (2S3) (2019) 971-975, https://doi.org/10.35940/ijrte. B1182.0782S319.

[17] S.A. Khan, A. Aabid, I. Mokashi, Z. Ahmed, Effect of micro jet control on the flow filed of the Duct at Mach 1.5, Int. J. Recent Technol. Eng. 8 (2S8) (2019) 17581762, https://doi.org/10.35940/ijrte.B1148.0882S819.

[18] M. Faheem, M. Kareemullah, A. Aabid, I. Mokashi, S.A. Khan, Experiment on of nozzle flow with sudden expansion at mach 1.1, Int. J. Recent Technol. Eng. 8 (2 Special Issue 8) (2019) 1769-1775, https://doi.org/10.35940/ijrte. B1150.0882S819.

[19] S.A. Khan, Z. Ahmed, A. Aabid, I. Mokashi, Experimental research on flow development and control effectiveness in the duct at high speed, Int. J. Recent Technol. Eng. 8 (2 Special Issue 8) (2019) 1763-1768, https://doi.org/ 10.35940/ijrte.B1149.0882S819.

[20] R. Ramesh Kumar, Y. Devarajan, CFD simulation analysis of two-dimensional convergent-divergent nozzle, Int. J. Ambient Energy (2020), https://doi.org/ 10.1080/01430750.2018.1517683.

[21] S. Ramanjaneyulu, Design and flow analysis of convergent divergent nozzle using CFD, Int. J. Res. Appl. Sci. Eng. Technol. 7 (4) (2019) 4020-4029, https:// doi.org/10.22214/ijraset.2019.4672.

[22] S.A. Khan, M. Mohiuddin, A.S. C, A.G.M. Fharukh, Investigation of the effects of nozzle exit mach number and nozzle pressure ratio on axisymmetric flow through suddenly expanded nozzles, Int. J. Eng. Adv. Technol. 8 (3) (2019) 570-578.

[23] A. Aabid, S.A. Khan, Investigation of high-speed flow control from CD nozzle using design of experiments and CFD methods list of symbols, Arab. J. Sci. Eng. (2020), https://doi.org/10.1007/s13369-020-05042-z.

[24] M.F.M. Sajali, A. Aabid, S.A. Khan, A.G.M. Fharukh, E. Sulaeman, Numerical investigation of flow field of a non-circular cylinder numerical investigation of flow field of a non-circular cylinder, CFD Lett. 11 (5) (2019) 37-49.
[25] S.A. Khan, A. Aabid, M.A.A. Baig, CFD analysis of cd nozzle and effect of nozzle pressure ratio on pressure and velocity for suddenly expanded flows, Int. J. Mech. Prod. Eng. Res. Dev. 8 (3) (2018) 1147-1158, https://doi.org/10.24247/ ijmperdjun2018119.

[26] A. Khan, A. Aabid, S.A. Khan, CFD analysis of convergent-divergent nozzle flow and base pressure control using micro-JETS, Int. J. Eng. Technol. 7 (3) (2018) 29.

[27] S.A. Khan, A. Aabid, A.G.M. Fharukh, A.A. Al-Robaian, A.S. Alsagri, Analysis of area ratio in a CD nozzle with suddenly expanded duct using CFD method, CFD Lett. 11 (5) (2019) 61-71.

[28] A. Aabid, A. Khan, N.M. Mazlan, M.A. Ismail, M.N. Akhtar, S.A. Khan, Numerical simulation of suddenly expanded flow at mach 2.2, Int. J. Eng. Adv. Technol. 8 (3) (2019) 452-457.

[29] A.G.M. Fharukh, A.A. Alrobaian, A. Aabid, S.A. Khan, Numerical analysis of convergent-divergent nozzle using finite element method [Online]. Available: Int. J. Mech. Prod. Eng. Dev. 8 (6) (2018) 373-382. www.tjprc.org.

[30] S.A. Khan, A. Aabid, I. Mokashi, A.A. Al-Robaian, A.S. Alsagri, Optimization of two-dimensional wedge flow field at supersonic mach number, CFD Lett. 11 (2019) 80-97.

[31] S.A. Khan, A. Aabid, A.S, C, CFD Simulation with analytical and theoretical validation of different flow parameters for the wedge at supersonic mach number, Int. J. Mech. Mechatron. Eng. 19 (1) (2019) 170-177.

[32] M.F.M. Sajali, A. Aabid, S.A. Khan, F.A.G. Mehaboobali, E. Sulaeman, Numerical investigation of flow field of a non-circular cylinder, CFD Lett. 11 (5) (2019) 37-49.

[33] M.F.M. Sajali, S. Ashfaq, A. Aabid, S.A. Khan, Simulation of effect of various distances between front and rear body on drag of a non-circular cylinder, J. Adv. Res. Fluid Mech. Therm. Sci. 62 (1) (2019) 53-65.

[34] A. Afzal, A. Aabid, A. Khan, S.A. Khan, T. Nath, R. Kumar, Response surface analysis, clustering, and random forest regression of pressure in suddenly expanded high-speed aerodynamic flows, Aerosp. Sci. Technol. 107 (2020) 106318, https://doi.org/10.1016/j.ast.2020.106318.

[35] T. Al-khalifah, A. Aabid, S.A. Khan, Regression analysis of flow parameters at high mach numbers, Solid State Technol. 63 (6) (2020) 5473-5488.

[36] A. Kumar, G. Balu, S. Panneerselvam, E. Rathakrishnan, Performance of an isolator fed with parallel flow, in: 41st AIAA/ASME/SAE/ASEE Joint Propulsion Conference and Exhibit no. July, 2005, pp. 1-13, https://doi.org/10.2514/ 6.2005-4380. 